\title{
GÊNERO, TEMPOS DE TRABALHO E PANDEMIA: POR UMA POLÍTICA CIENTÍFICA FEMINISTA ${ }^{1}$
}

\author{
GENDER, WORKING TIME AND PANDEMIC: TOWARDS A FEMINIST SCIENTIFIC \\ POLITICS
}

\author{
Bárbara Castro ${ }^{2}$ \\ Mariana Miggiolaro Chaguri ${ }^{3}$
}

\begin{abstract}
Resumo: A adoção de medidas de isolamento social em diferentes partes do mundo como estratégia para o enfrentamento da pandemia do Covid-19 ampliou os debates sobre a sobrecarga de trabalho de mulheres. Dialogando com tais questões, este artigo debate a reorganização do trabalho nas universidades e centros de pesquisa durante o isolamento social, focalizando as assimetrias e as desigualdades de gênero induzidas ou evidenciadas pelo trabalho remoto. Argumentando sobre a necessidade de um tempo próprio para o trabalho intelectual de mulheres, o artigo sugere a adoção de uma política científica feminista.
\end{abstract}

Palavras-chaves: Gênero; feminismo; mulheres na ciência.

Abstract: Social isolation had become a primary measure to contain COVID-19 worldwide, and it has increased debates about gender inequality. Regarding such topics, this paper debates the reorganization of work in universities during social isolation, focusing on asymmetries and gender inequalities induced or evidenced by remote work. We argue about the different impacts of care at women's work at home and universities. Closing our argument, we suggest the adoption of feminist scientific policy.

Keywords: Gender; feminist; women in sciences.

\section{Introdução}

Tornaram-se amplos e recorrentes os debates e as reflexões a respeito da sobrecarga de trabalho enfrentada por mulheres durante o isolamento social, medida adotada em diferentes partes do mundo como estratégia para o enfrentamento da pandemia da Covid-19. Temas como divisão do trabalho doméstico e do cuidado com os membros da família (crianças ou não) tornaram-se objeto da reflexão de especialistas em diferentes áreas e campos do conhecimento, bem como foram verbalizados por diferentes mulheres em intervenções ou relatos mais ou menos públicos.

Em todos os casos, esteve em questão debater e refletir sobre os impactos cotidianos das associações - simbólicas e materiais - entre o feminino e o cuidado. Para abordar a questão, recortamos a sobreposição entre tempos e espaços de trabalho de professoras e pesquisadoras no momento em que aulas, pesquisas e demais atividades administrativas das universidades e dos institutos de pesquisa estão se desenvolvendo remotamente, arremedando uma situação de normalidade, numa tendência que, ao menos no Brasil, marcará o ano de $2020^{4}$.

O extraordinário da pandemia, expresso tanto no isolamento social quanto no trabalho remoto, tem nos colocado diante do ordinário das assimetrias das relações de gênero numa dupla frente: o cotidiano das atividades de ensino, pesquisa e administração nas universidades;

\footnotetext{
${ }^{1}$ Uma primeira versão deste artigo foi publicada no Blog DADOS. Ver: Castro e Chaguri (2020).

${ }^{2}$ Universidade Estadual de Campinas, Campinas, São Paulo Brasil.

${ }^{3}$ Universidade Estadual de Campinas, Campinas, São Paulo Brasil.

${ }^{4}$ No momento em que escrevemos este texto, a curva de contágio da COVID-19 segue ascendente e ultrapassamos o número de 50 mil mortes. Ver: UOL (2020).
} 
e a dinâmica própria da produção do conhecimento científico. Enquanto em contextos ordinários, mulheres na ciência lidam com ambientes mais ou menos hostis no que se refere ao assédio moral ou sexual, além de enfrentarem uma sobrecarga de trabalho administrativo em posições menos prestigiosas da burocracia universitária ${ }^{5}$, por exemplo, as medidas de isolamento social para o enfrentamento da pandemia do Covid-19 incidiram exatamente na ambiguidade da posição de mulheres: entre a casa e a universidade; entre o trabalho de cuidado, o trabalho emocional e o trabalho intelectual.

\section{A casa, a universidade e os tempos de trabalho}

Analisar desigualdades de gênero em um contexto no qual a casa se torna o espaço de trabalho das mulheres nos remete, quase de imediato, àquelas que residem em unidades familiares compartilhadas com companheiros e filhos, especialmente pequenos. Nessa cena, as atividades da vida doméstica, como limpeza, preparo de refeições e atenção aos filhos, se confundem com as atividades com demandas variadas da vida profissional, como lecionar, orientar, ler e revisar textos, dar pareceres, redigir artigos, participar de seminários ou de reuniões administrativas em ambiente virtual, entre outras. A sobreposição de tarefas, espaços e tempos tem se mostrado, por si só, exaustiva para homens e mulheres em trabalho remoto. No entanto, enquanto o tempo e o espaço das atividades laborais dos homens tendem a ser preservados e respeitados, mulheres nas mesmas condições têm relatado ${ }^{6}$ a constância das interrupções pelas crianças e por outros membros da família, o que, no caso específico das professoras e pesquisadoras, torna impossível a concentração constante e duradoura que é exigida para o conjunto de tarefas que conformam o conteúdo de seu trabalho.

Habitualmente, em alguns momentos do dia - em geral, com crianças na escola e demais membros da família ausentes -, a casa representava para muitas professoras e pesquisadoras um espaço de refúgio para que pudessem trabalhar concentradas e sem interrupções, o que, muitas vezes, a rotina cotidiana no espaço físico da universidade não possibilitava: atividades que exigem concentração eram constantemente interrompidas por demandas variadas de colegas e estudantes. Na pandemia, a sobreposição permanente entre casa e trabalho remunerado converteu a casa em um espaço constantemente perturbador para o exercício de grande parte do trabalho intelectual e criativo de mulheres.

Se a sobrecarga de trabalho para as que são mães é evidente e deve ser reconhecida pela comunidade científica - e também pelas agências de fomento -, é preciso destacar que as associações diretas entre gênero e maternidade podem reforçar uma leitura naturalista sobre as desigualdades de gênero na ciência que, no limite, faz equivaler professores e pesquisadores homens a pares mulheres sem filhos. Ao associar a desigualdade de gênero à maternidade, $\mathrm{o}$ efeito social, político e prático é reduzir a multiplicidade de relações de poder que constituem a vida social das mulheres e que produzem a ideia do que é ser mulher e limitar a apenas uma dessas facetas o alcance de reivindicação pela igualdade de gênero.

Argumentamos, assim, que, embora seja fundamental tratar da sobrecarga das mulheres que são mães, dirigir a crítica social apenas a esse arranjo social e familiar acaba por invisibilizar algumas das inovações teóricas e normativas mais potentes no campo de

\footnotetext{
5 Para um balanço a partir de dados da alocação institucional de professoras na Universidade Estadual de Campinas, ver Moschkovich e Almeida (2015).

${ }^{6}$ Para uma perspectiva sobre a questão, ver: Schreiber (2020); García-Bullé (2020). Desigualdades de gênero na ciência durante a quarentena podem ser percebidas, por exemplo, na queda substantiva na quantidade de submissão de artigos científicos assinados por autoras, seja em autoria única ou não. Para um panorama do caso brasileiro, ver: Candido e Campos (2020).
} 
estudos feministas e de gênero: as distribuições desiguais de poder entre homens e mulheres, presentes em nossa sociedade, não derivam da natureza biológica do homem ou da mulher - ao contrário, são socialmente construídas. Justamente por isso, temos no horizonte possibilidades de pensar na subversão e na superação de tais relações de poder.

Entre outras teóricas, Elisabeth Badinter (2011) nos faz pensar sobre como o ideal do que é ser uma "boa mãe" muda conforme o contexto social e o tempo histórico. As expectativas sociais em torno dos papéis que pais e mães devem exercer são produto das desigualdades de poder entre homens e mulheres e das constantes lutas, da parte delas, por maior autonomia econômica e de tempo.

Se nos anos 1970, no contexto francês, a luta feminista era por uma maior autonomia das mães em relação aos bebês e às crianças, no atual contexto estaríamos vivendo o que a autora chama de "ofensiva naturalista". Em contraponto às pílulas anticoncepcionais, a mamadeira e mulheres trabalhando "fora de casa", promover-se-ia agora a amamentação por livre demanda, recusa a qualquer forma de leite artificial e recusa ao trabalho nos primeiros anos do bebê. Ou arranjos laborais que permitam às mães trabalhar estando próximas dos bebês - como o trabalho remoto, autônomo ou pequenos empreendimentos individuais ou familiares.

Em ambos os casos, estamos diante de tecnologias biopolíticas e de arranjos laborais e sociais que organizam um controle sobre o tempo da vida: as pílulas controlam o tempo da gravidez; a cesária, o tempo do parto; a mamadeira, o tempo da amamentação, por exemplo. Avançando o argumento, vemos que não se trata apenas de processos biológicos, mas de uma ideologia maternalista à qual se adere ou não no campo das ideias e que é atravessada, na prática social, por diferenças de classe, raça e políticas de Estado.

Assim sendo, a existência de creches e o acesso universal a elas, o direito e o tempo de duração de licenças maternidade e/ou paternidade são exemplos de como o próprio Estado e suas políticas públicas são pensados e de como essas são produzidas a partir de um repertório ideológico sobre as responsabilidades distintas que homens e mulheres têm em relação ao cuidado com os filhos, especialmente nos primeiros meses de vida. Desse modo, o Estado é reprodutor de ideologias maternalistas e de normas de gênero vinculadas à ideia da continuidade entre biologia e cultura.

Longe de esgotar esse debate, nós o retomamos aqui para destacar que partilhamos da ideia de que a maternidade não deve ser vista apenas pela perspectiva biológica. Ao contrário, olhar para ela revela como o gênero é socialmente construído. Mais do que isso, para pensar nos relatos de sofrimento em tempos de pandemia, é preciso indagar o quanto esses ideais atuam, promovendo um novo repertório de opressão às mulheres, pois quem não pode exercer a "boa maternidade" sofre tanto com o julgamento social quanto com o sentimento de culpa por não alcançar esse ideal.

Em um contexto de isolamento social no qual os filhos dividem o mesmo espaço com as mães em tempo integral, esse ideal do exercício da maternidade torna-se permanentemente disputado (entre as mulheres mães e os filhos, entre as mulheres mães e seus companheiros, entre as mulheres mães e outras mães, os familiares, as amigas e os colegas). Como consequência, ao trabalho emocional de construir os limites da prática da "boa maternidade", foram acrescentadas, também, negociações mais ou menos conflitivas sobre os usos do espaço doméstico e sobre o tempo dedicado às variadas tarefas, implicando numa sobrecarga de trabalho emocional e de cuidado, atento aos detalhes e às nuances das relações pessoais e afetivas.

Sandra Burchi (2018) indica essa questão em contexto não pandêmico. Sua pesquisa sobre mulheres italianas que trabalhavam em casa (home office) demonstra como elas buscavam organizar seu tempo e espaço de trabalho de modo a reduzir o conflito com o restante da casa. O que chama a atenção é que a principal estratégia destacada pela autora é a de que as mulheres controlavam muito bem seu tempo de trabalho em casa para evitar que seu espaço fosse compartilhado com outros membros da casa enquanto estavam trabalhando. Organizavam, assim, um território livre de 
interrupções e de competição de atenção por outras tarefas, atividades e demandas - domésticas ou emocionais. No contexto da pandemia, essa separação não é mais possível, especialmente em domicílios que não contam com espaços exclusivos para o exercício do trabalho.

Neste ponto, a sociologia das feministas materialistas francesas pode nos ajudar a compreender o quanto de trabalho emocional e de cuidado informa a negociação quase permanente de dias e horários para cada tarefa doméstica, para atividades em família, para tempos de silêncio absoluto. A separação e a hierarquização das tarefas entre homens e mulheres, a reposição das responsabilidades domésticas e o cuidado com elas e a soma dessas atividades com as do trabalho remunerado são a base da teoria da divisão sexual do trabalho, cujas referências principais são Helena Hirata e Danièle Kergoat. Adicionamos a essa perspectiva o debate feminista que tem como foco a discussão sobre os tempos sociais.

Nos anos 1970, o movimento feminista francês denunciava a "dupla jornada" das mulheres trabalhadoras, que somavam o trabalho produtivo, remunerado, ao reprodutivo, não remunerado. Naquele momento, já era comum ouvir a defesa do trabalho em tempo parcial ou em regime flexível de horários como forma de conciliar as duas atividades e garantir a maior participação das mulheres no mercado de trabalho. Mas seria suficiente assegurar formas de maior participação das mulheres no mercado de trabalho para combater a desigualdade de gênero e prover a autonomia das mulheres?

Em meados dos anos 1980, Monique Haicault cunhou a ideia de "carga mental" para descrever o constante cansaço que sentiam as mulheres que se inseriam no mundo do trabalho. Haicault teve larga experiência de pesquisa com mulheres que trabalhavam a domicílio na indústria têxtil, sobrepondo espaços e tempos de trabalho. Mas foi quando ela deslocou sua pesquisa para outro contexto, mulheres trabalhando em fábricas, fora de casa, que ela pôde perceber como a distinção de espaços sociais era simplesmente de ordem simbólica. Na fábrica, as mulheres planejam a vida doméstica, pensam sobre as compras da semana e do mês, nas contas a pagar e nas tarefas que têm para cumprir, ou seja, a casa as acompanha na fábrica, de modo que a carga mental não está na justaposição ou na somatória de atividades, mas na sua sincronicidade, na sua simultaneidade.

A carga mental é feita, portanto, de ajustes perpétuos, da viscosidade do tempo que raramente é ritmado e muito mais frequentemente imanência, onde se perde o corpo e a cabeça para calcular o incalculável, para recuperar o atraso do tempo com o tempo, para tentar gerenciar com o tempo, o tempo perdido. A carga mental está cheia desses pequenos censores que dizem de maneira simples e tão frequente: "Não tenho tempo". (HAICAULT, 1984, p. 275, tradução livre)

Décadas antes, em palestra intitulada "Profissões para mulheres", realizada em 1931 às integrantes do Junior Council da London and National Society for Women's Service, Virginia Woolf observava que, independente de suas respectivas profissões, mulheres profissionais precisariam matar o "anjo da casa", uma espécie de duplo da socialização feminina, "[...] imensamente compreensiva. [...] imensamente encantadora. [...] absolutamente altruísta. [...] que sacrificava diariamente" (WOOLF, 2019, p. 47). No argumento da escritora, desobrigar-se do trabalho de cuidado e das normas de conduta de gênero a ele associados, tais como o altruísmo, a humildade suplicante e a docilidade seria fundamental para promover quebras nas pontes que ligam a casa privada ao mundo da vida pública, desorganizando assim as associações entre o feminino e o cuidado, e liberando - tempo e espaço - para que mulheres desenvolvam suas aptidões intelectuais desobrigadas da sobrecarga advinda dessa socialização.

Em outro ensaio, publicado dois anos antes, Virginia Woolf refletiu sobre as possibilidades de criação e invenção das mulheres na ficção, afirmando que tal tipo de trabalho implicava em um 
espaço exclusivo para seu próprio trabalho, condição necessária para desenvolver suas habilidades intelectuais e criativas. À célebre citação da autora: "uma mulher precisa ter dinheiro e um teto todo seu, um espaço próprio" (WOOLF, 2014, p. 12), adicionaremos que ter um espaço só para si é o que permite a diferentes mulheres ter um tempo só para si, suspendendo os imperativos ou as demandas derivadas daquele duplo da socialização acima mencionado.

Ou seja, além da autonomia econômica, as mulheres precisam ter acesso a alguma autonomia de tempo para poderem se concentrar nas suas atividades criativas. Esse tempo só para si corresponde, afinal, aos períodos de disponibilidade para si e de concentração que permitem desenvolver ou aprimorar as habilidades de imaginar e criar, características-chave da inovação científica.

No entanto, a realização de trabalhos que exigem alta concentração não combina com uma rotina de interrupções. Conforme indicado por pesquisas conduzidas por Bárbara Castro, homens e mulheres têm percepções distintas de produtividade quando atuam em home office: elas avaliam que rendem menos, por serem interrompidas o tempo todo por outras pessoas e responsabilidades; eles ponderam que rendem mais, pois trabalham concentrados e sem interrupção de outras pessoas e tarefas domésticas ${ }^{7}$.

Aqui, cabe destacar as experiências desiguais que diferentes mulheres possuem nas relações com o espaço doméstico, bem como nas relações familiares, em suas demandas e tarefas. Hirata e Kergoat (2007) propuseram que nomeemos as atuais estratégias de articulação entre vida profissional e familiar como "modelo de delegação", isto é, mais do que conciliação ou articulação entre ambas atividades, o que a prática social revela é o uso que mulheres de classe média fazem do trabalho de outras mulheres - no contexto francês, geralmente imigrantes, no contexto brasileiro, geralmente mulheres negras - para construir suas carreiras profissionais. Esse modelo de delegar para outras mulheres as atividades domésticas e do cuidado só é possível por conta da polarização do emprego das mulheres. Ainda assim, sugerem:

Mesmo que exista delegação, um de seus limites está na própria estrutura do trabalho doméstico e familiar: a gestão do conjunto do trabalho delegado é sempre da competência daquelas que delegam [...] A nosso ver, é preciso questionar, sobretudo, os âmbitos psicológicos da dominação e a dimensão da afetividade. (HIRATA; KERGOAT, 2007, p. 607-8)

Adicionando o debate sobre os tempos sociais, as mulheres de classe média, para terem tempo de trabalho liberado, planejam, organizam e fiscalizam a atividade de outras mulheres que contratam para cuidar da sua casa e de seus filhos Entretanto, não deixam de sentir a carga mental por essa supervisão, e também a culpa pelo exercício de um cuidado não padrão. A pessoa contratada, por sua vez, para poder assumir essa tarefa profissionalmente, vive também a experiência de deixar seus filhos e sua casa por conta de outras mulheres.

A casa não é, portanto, apenas espaço das relações privadas, é também produtora e reprodutora de normas, regras e valores sociais, bem como hierarquias, disputas e conflitos de gênero. Ainda, retomando a bandeira feminista dos anos 1970, o privado é político, e as negociações e os conflitos que se desenrolam no espaço doméstico são reveladores das relações de poder que são histórica e socialmente construídas 8 .

\footnotetext{
7 Projeto "Cartografias do trabalho na sociedade contemporânea: impactos das políticas trabalhistas e sociais neoliberais nas dinâmicas de desigualdade de classe, gênero e raça”, desenvolvido no Centro de Sociologia Contemporânea do IFCH/Unicamp.

${ }^{8}$ Suely Kofes (2001) defende que o doméstico é um lugar estrutural que, mais do que repor a dicotomia público e privado, revela suas articulações, em que a organização familiar e afetiva se articula com desigualdades de classe e hierarquias raciais. Assim, as relações políticas entre patroas e empregadas domésticas se repõem no privado.
} 


\section{Uma política científica feminista}

Articulando os argumentos apresentados até aqui, podemos considerar que o duplo da socialização feminina ao qual se refere Virgínia Woolf marca um conjunto de expectativas profissionais sobre mulheres, feitas por empregadores, por pares e por nós mesmas. No caso das universidades, atravessam também as expectativas institucionais sobre as habilidades e competências de suas colegas: a professora empática; a colega de departamento disponível para cuidar da harmonia do ambiente de trabalho; a chefe cuja autoridade é disputada nos seus mínimos - e sutis - detalhes; a especialista em gênero que recebe e encaminha as denúncias de violência e assim por diante.

No seminário "Présences sociales: genre, care et temporalités", Marc Bessin apresentou alguns dos resultados parciais de sua pesquisa, que apontam para o modo como a dimensão do cuidado atravessa os diferentes tipos de trabalho organizados no ambiente universitário. Para o autor, o espaço universitário repõe relações de poder e, por isso, constrói relações de sofrimento e, consequentemente, torna-se um espaço para a circulação do cuidado. Na ementa de seu seminário, por exemplo, o sociólogo menciona, para o circuito de cuidados que se colocam nas práticas de pesquisa: "as práticas de ajuda mútua, de trabalho coletivo, para ver como as presenças podem contribuir para resistir a uma produção de conhecimento concebida apenas em uma lógica de competição que induz fortes tensões e muitos de sofrimento" "9. Pensando na dimensão do trabalho de ensino, poderíamos referenciar a acolhida de estudantes com necessidades específicas e o apoio emocional construído na relação de orientação.

Deslocando tais questões para os tempos de isolamento social, indicamos que esse contexto tornou permeáveis as nuances entre o público e o privado que, desde o início de suas trajetórias como estudantes universitárias, mulheres cientistas são obrigadas a aprender a negociar. Uma negociação de tempos e espaços sempre penosa e carregada por um sem número de inseguranças e frustrações, as quais, num momento como este, são também reveladoras das dificuldades para se falar sobre os motores da produção da desigualdade baseada em gênero na ciência.

Gostaríamos, portanto, de deslocar o debate da unidade familiar, para a maneira como essas regras e normas de gênero que produzem o cuidado como atividade feminina levam à vivência da carga mental de mulheres cientistas, casadas ou solteiras, com ou sem filhos.

Ao sermos socialmente produzidas para preocupar-nos com pai e mãe, amigos e amigas, sobrinhos e sobrinhas, também nos dedicamos a pensar em regras e normas de quarentena acadêmicas que sejam sensíveis à heterogeneidade de situações de nossos(as) colegas e estudantes. Disputamos as regras universalistas da burocracia pontuando essas diferenças. E à carga mental do cuidado com a família e afins adiciona-se a do cuidado com o(a) outro(a) no espaço de trabalho.

Carreiras científicas são alicerçadas em noções de mérito e no reconhecimento por pares. Compreender a dinâmica da produção do conhecimento científico também como a história da produção da diferença baseada em gênero implica na desestabilização de tais noções, o que não deixa de nos colocar em posições desconfortáveis e, por isso mesmo, muitas vezes negligenciadas. O universalismo da posição social dos homens acaba se desdobrando no universalismo também de suas ideias, de modo que falar sobre a desigualdade de gênero na produção do conhecimento nos põe uma questão incômoda: ao reconhecer sua diferença em relação aos pares homens, estariam as mulheres admitindo sua incapacidade para jogar os jogos

\footnotetext{
${ }^{9}$ Seminário anual do autor na EHESS, acompanhado por Bárbara Castro durante a realização de seu pósdoutoramento financiado pelo Programa CAPES-DOFECUB no âmbito do projeto "Trabalho no Brasil e na França: sentido das mudanças e mudanças de sentido" (EDITAL No. 16/2015), liderado por Aparecida Neri de Souza e Régine Bercot. O programa do seminário atual se encontra aqui: https://enseignements2019.ehess.fr/2019/ue/1022/.
} 
dentro das mesmas regras meritocráticas e, por extensão, estariam reconhecendo o particularismo ou a marginalidade do conhecimento que produzem?

De modo amplo, sustentamos que mulheres cientistas são cotidianamente - em tempos de pandemia ou não - empurradas para universos de produção do conhecimento academicamente confinados, enfrentando desconfianças ou condescendências quanto ao alcance e ao potencial de suas ideias e inovações ${ }^{10}$.

No extraordinário dos tempos de isolamento social, as dificuldades ordinárias se fazem ainda mais presentes e nos tornam incapazes de seguir a penosa negociação entre público e privado sobre a qual organizamos nossas carreiras. O modelo de delegação que permitia a liberação de tempo para o trabalho implodiu com a pandemia. Como efeito, mulheres cientistas estão ainda mais confinadas em suas possibilidades de encontrar tempo e espaço para pesquisar, estudar e analisar um fenômeno cujos impactos em todas as áreas do conhecimento são notáveis.

Tais dificuldades, sugerimos, apenas podem ser superadas na medida em que noções de mérito, produtividade e trabalho institucional sejam rearticuladas em termos de uma política científica feminista, baseada no reconhecimento das injustiças de gênero, assim como daquelas baseadas em raça e sexualidade, sobre as quais, ao fim e ao cabo, a produção científica do conhecimento e a rotina administrativa das universidades ao redor do mundo se assentam. $\mathrm{Ou}$ seja, a desigualdade de gênero na ciência não pode ser tratada como uma excepcionalidade das medidas tomadas por universidades para o enfrentamento da pandemia do Covid-19. Antes, a pandemia revela relações de poder que são invisibilizadas na experiência cotidiana.

Apontamos que, por mais persistentes, competentes ou disciplinadas que mulheres cientistas sejam, não é possível imaginar que desigualdades de gênero que estruturam a produção do trabalho científico sejam superáveis por meio da força de vontade ou do comprometimento individual. As soluções para o chamado gender gap na produção científica não podem ser individualizadas, sob pena de naturalizar a diferença de gênero e, sobretudo, penalizar ainda mais mulheres sobrecarregadas com seus trabalhos de cuidado, a despeito de seus méritos acadêmicos.

Argumentamos sobre a necessidade de uma política científica feminista, baseada na promoção de um ambiente acadêmico e profissional de respeito à diferença que marca a atuação profissional de mulheres cientistas, no estímulo às suas ideias e inovações, bem como na necessária e urgente dissociação entre trabalho das mulheres e trabalho emocional e de cuidado.

Uma política científica feminista pretende, assim, que mulheres cientistas não sejam lembradas como as pioneiras que estiveram à frente de seu tempo; antes, tal política visa garantir que mulheres existam intelectualmente em seu tempo presente, participando ativamente das controvérsias públicas e dos imperativos da inovação científica que a sociedade nos demanda a cada momento da história. Para tanto, é necessário encarar aquilo que as desigualdades sociais entre mulheres permitiam invisibilizar ou amenizar.

É preciso revisitar os modos de reprodução subjetiva da dimensão da afetividade e tornar real o "paradigma da parceria", que "considera mulheres e homens como parceiros (e portanto decorre mais de uma lógica de conciliação de papéis que do conflito e da contradição) e as relações entre eles mais em termos de igualdade que de poder" (HIRATA; KERGOAT, 2007, p. 604).

\footnotetext{
${ }^{10}$ Sobre isso, acompanhar a iniciativa da ANPOF, Mulheres na Filosofia, que menciona os espaços específicos que as mulheres ocupam dentro do campo de conhecimento da filosofia. Em entrevista a Nadia Junqueira Ribeiro, Yara Frateschi destaca que "na Unicamp, por exemplo, a pós-graduação em filosofia é a mais desequilibrada do IFCH (a média do IFCH é de aproximadamente $50 \%$ de mulheres enquanto na filosofia apenas $24,56 \%$ são mulheres) e, mais impressionante ainda, o PPG de filosofia é mais desigual do que a pós-graduação do Instituto de Matemática e Computação (31,60\% de mulheres) e do Instituto de Física (27,88\% de mulheres)". Disponível em: http://anpof.org/portal/index.php/en/2014-01-07-15-22-21/entrevistas/2186-mulheres-na-filosofia-nos-queremos-nosjuntar-a-eles-entrar-pela-porta-da-frente-entrevista-com-prof-yara-frateschi-unicamp.
} 
Se este modelo tem sido pensado em nível de práticas individuais, é preciso repensar o que nós, mulheres, demandamos também do Estado - e, mais proximamente, das instituições nas quais trabalhamos. Se há mulheres que ultrapassaram barreiras de gênero, classe e, mais raramente, raça, para se inserir em postos de trabalho nas universidades, isso reforça nosso argumento de que, se o capital econômico e cultural auxilia algumas mulheres a ter mais tempo livre, não as livra da desigualdade de gênero inerente à sua socialização como mulheres.

Transformar cultural e politicamente as normas e as expectativas de gênero na ciência demanda mais do que arranjos individuais. Implica que, se o Estado não assegurar políticas para a igualdade de gênero, ao menos as instituições de trabalho e/ou os sindicatos de docentes, pesquisadoras e trabalhadoras assegurem normativas e espaços de formação que promovam a redistribuição da sobrecarga do trabalho emocional e do cuidado das acadêmicas. A preocupação com igualdade de gênero deve implicar não apenas na ampliação da contratação e da participação das mulheres, mas também na transformação da cultura sexista que se reproduz também nesse espaço de trabalho. Como espaço de inovação, as comunidades universitárias devem ser capazes de reinventar práticas de trabalho que reduzam os impactos das desigualdades advindas da socialização de gênero às mulheres. Tornar visível e reconhecer essa sobrecarga é um primeiro passo.

\section{Referências}

BADINTER, E. O conflito: a mulher e a mãe. Rio de Janeiro: Record, 2011.

BURCHI, S, Economias domésticas. Trabalhar em casa em tempos de precariedade. Novas profissões e espaços de vida. Laplage em revista, vol. 4, n. 1, p. 21-35, $2018 . \quad$ Disponível em: https://www.laplageemrevista.ufscar.br/index.php/lpg/article/view/434.

CANDIDO, M. R.; CAMPOS, L. A. Pandemia reduz submissões de artigos acadêmicos assinados por mulheres. Blog DADOS, Rio de Janeiro, 14 maio 2020. Disponível em: http://dados.iesp.uerj.br/pandemia-reduz-submissoes-de-mulheres/. Acesso em: 20 maio 2020.

CASTRO, B.; CHAGURI, M. Um tempo só para si: gênero, pandemia e uma política científica feminista. Blog DADOS, Rio de Janeiro, 22 maio 2020. Disponível em: http://dados.iesp.uerj.br/pandemia-cientifica-feminista/. Acesso em: 15 jun. 2020.

GARCÍA-BULLÉ, S. Quarantine and gender inequality in academia. Observatory of Educational Innovation - Tecnológico de Monterrey. Disponível em: https://observatory.tec.mx/edu-news/women-academics-covid19. Acesso em: 15 jun 2020.

HAICAULT, M. La gestion ordinaire de la vie en deux. Sociologie du Travail, Elsevier Masson, ano 26 - Travail des femmes et famille, n. 3, p. 268-277, 1984.

HIRATA, H.; KERGOAT, D. Novas configurações da divisão sexual do trabalho. Cadernos de Pesquisa, São Paulo, v. 37, n. 132, dez. 2007. Disponível em: http://www.scielo.br/scielo.php?script=sci_arttext\&pid=S0100-15742007000300005\&lng=en\&nrm=iso. Acesso em: 19 maio 2020.

KOFES, S. Mulher, mulheres: identidade, diferença e desigualdade na relação entre patroas e empregadas. Campinas, Editora da Unicamp, 2001. 
MOSCHKOVICH, M.; ALMEIDA, A. M. F. Desigualdades de gênero na carreira acadêmica no Brasil. Dados, Rio de Janeiro, v. 58, n. 3, set. 2015. Disponível em: http://www.scielo.br/scielo.php?script=sci_arttext\&pid=S0011-52582015000300749\&lng=en\&nrm=iso. Acesso em: 19 maio 2020.

SCHREIBER, M. Female scientists are bearing the brunt of quarantine child-rearing. The New Republic, 22 maio 2020. Disponível em: https://newrepublic.com/article/157785/femalescientists-bearing-brunt-quarantine-child-rearing. Acesso em: 14 jun. 2020.

UOL. Brasil tem 1.103 novas mortes em 24 h, diz consórcio; total chega a 53.874. Disponível em: https://noticias.uol.com.br/saude/ultimas-noticias/redacao/2020/06/24/coronavirus-covid19-casosmortes-brasil-24-junho.htm. Acesso em: 25 jun. 2020.

WOOLF, V. Um teto todo seu. São Paulo: Tordesilhas, 2014.

WOOLF, V. Profissões para mulheres. In: WOOLF, V. As mulheres devem chorar... ou se unir contra a guerra. São Paulo: Autêntica, 2019.

\section{Sobre as autoras}

Bárbara Castro é graduada (Universidade Estadual de Campinas), tem Mestrado em Ciência Política (Universidade Estadual de Campinas) e Doutorado em Ciências Sociais (Universidade Estadual de Campinas). É professora da Universidade Estadual de Campinas. Tem experiência na área de Sociologia, com pesquisa nos seguintes temas: estudos de gênero, sociologia do trabalho e tempos sociais.

E-mail: bgcastro@unicamp.br.

Mariana Miggiolaro Chaguri é graduada em Ciências Sociais (Universidade Estadual de Campinas), tem Mestrado em Sociologia (Universidade Estadual de Campinas) e Doutorado em Sociologia (Universidade Estadual de Campinas). É professora da Universidade Estadual de Campinas. Tem experiência na área de Sociologia, com pesquisa nos seguintes temas: estudos de gênero, sociologia rural, pensamento social e estudos pós-coloniais.

E-mail: chaguri@unicamp.br. 